\title{
Successful expansion of functional and stable regulatory $T$ cells for immunotherapy in liver transplantation
}

\author{
Niloufar Safinia ${ }^{1, *}$, Trishan Vaikunthanathan ${ }^{1, *}{ }^{,}$Henrieta Fraser ${ }^{1}$, Sarah Thirkell ${ }^{1}$, \\ Katie Lowe ${ }^{1}$, Laura Blackmore ${ }^{2}$, Gavin Whitehouse ${ }^{2}$, Marc Martinez-Llordella ${ }^{2}$, \\ Wayel Jassem², Alberto Sanchez-Fueyo ${ }^{2}$, Robert I. Lechler ${ }^{1}$ and Giovanna \\ Lombardi ${ }^{1}$ \\ ${ }^{1}$ MRC Centre for Transplantation, Division of Transplantation Immunology and Mucosal Biology, King's College London, Guy's \\ Hospital, London, UK \\ 2 Institute of Liver Studies, King's College Hospital, London, UK \\ * Co-first author \\ Correspondence to: Niloufar Safinia, email: niloufar_safinia@yahoo.com
}

Giovanna Lombardi, email: giovanna.lombardi@kcl.ac.uk

Keywords: regulatory T cells, tolerance, immunotherapy, immunosuppression, liver transplantation, Immunology and Microbiology Section, Immune response, Immunity

Received: July 26, $2015 \quad$ Accepted: January 01, $2016 \quad$ Published: January 17, 2016

\section{ABSTRACT}

Strategies to prevent organ transplant rejection whilst minimizing long-term immunosuppression are currently under intense investigation with regulatory $\mathrm{T}$ cells (Tregs) nearing clinical application. The clinical trial, ThRIL, recently commenced at King's College London, proposes to use Treg cell therapy to induce tolerance in liver transplant recipients, the success of which has the potential to revolutionize the management of these patients and enable a future of drug-free transplants. This is the first report of the manufacture of clinical grade Tregs from prospective liver transplant recipients via a CliniMACS-based GMP isolation technique and expanded using anti-CD3/CD28 beads, IL-2 and rapamycin. We report the enrichment of a pure, stable population of Tregs $\left(>95 \% \mathrm{CD}^{+} \mathrm{CD} 25^{+} \mathrm{FOXP3} 3^{+}\right)$, reaching adequate numbers for their clinical application. Our protocol proved successful in, influencing the expansion of superior functional Tregs, as compared to freshly isolated cells, whilst also preventing their conversion to Th17 cells under pro-inflammatory conditions. We conclude with the manufacture of the final Treg product in the clinical research facility (CRF), a prerequisite for the clinical application of these cells. The data presented in this manuscript together with the much-anticipated clinical results from ThRIL, will undoubtedly inform the improved management of the liver transplant recipient.

\section{INTRODUCTION}

Liver transplantation remains the treatment of choice for patients with end stage liver disease. Therapeutic advances in immunosuppression have led to a dramatic improvement in allotransplantation, averting acute rejection and supporting short-term graft survival. However, the obligatory protracted use of powerful nonspecific immunosuppressants is complicated by increased morbidity and mortality as a result of chronic rejection and associated toxicity. The constant proportion of transplanted organs lost each year necessitating re-transplantation, in a climate of donor organ shortage, places further strain on an already saturated transplant waiting list.
The current approach to immunosuppression in transplantation is far from ideal with an enormous interest in the minimization/complete withdrawal of these drugs in liver transplant recipients. There have also been reports of a variable proportion of liver transplant recipients developing a state of 'operational' tolerance thus forgoing the requirements of therapeutic immunosuppression [1]. This phenomenon, however, only occurs late after transplantation and in a minority of patients [2]. It is, therefore, necessary to find novel strategies to allow for the development of tolerance early after transplantation and in turn negate the use of lifelong immunosuppression.

In this setting regulatory $\mathrm{T}$ cells (Tregs) are attractive candidates for therapeutic strategies aimed at 
tolerance induction, bearing in mind their integral role in promoting immune homeostasis. Characterised by the high and stable expression of surface interleukin-2 receptor $\alpha$ chain (IL-2R $\alpha, C D 25^{\text {hi }}$ ) and the transcription factor, FOXP3, these cells only constitute approximately 1-3\% of circulating $\mathrm{CD}^{+} \mathrm{T}$ cells in the periphery [3-5]. As such, recent advances permitting the expansion of these cells ex vivo presents an attractive opportunity in modulating immune responses through their adoptive transfer. We have shown that infusion of recipient murine Tregs, expanded in vitro, can prolong skin allograft survival and induce indefinite acceptance of heart allografts [6]. More recently, the adoptive transfer of polyclonal human Tregs in humanised mice protected from human skin pathology and induced increased survival of transplanted islets [7-9].

The posited implications of Treg cell therapy in the context of liver transplantation have been aptly construed in murine models whereby liver allografts from tolerant mice were infiltrated with Tregs, and the depletion of these cells resulted in a loss of tolerance [10]. This circumstance is further mirrored in human subjects with increased frequencies of Tregs reported in operationally tolerant liver transplant recipients [11] paralleled by low circulating levels during acute rejection [12]. As such, there is little doubt that Tregs are promising candidates for tolerance induction in liver transplantation.

To date no clinical trials addressing the safety and efficacy of Treg cell therapy in the induction of tolerance in solid organ transplantation have been described. Recent trials have primarily focused on the safety profile of Treg therapy in the setting of bone marrow transplantation [1315] and type I diabetes [16], with encouraging reports of efficacy. As a result, the prospects of applying Treg adoptive cell therapy in organ transplantation are now widely recognised.

In this regard, we have just opened the first combined Phase I/IIa clinical trial of Treg immunotherapy in the setting of liver transplantation, ThRIL (NCT02166177). Here, the safety, tolerability and efficacy of polyclonally expanded autologous Tregs from patients with end-stage liver disease, in combination with thymoglobulin and an mTOR-inhibitor-based immunosuppression regimen, will be assessed.

This is the first report, employing a Good Manufacturing Practice (GMP)-compliant protocol for the ex vivo expansion of Tregs from prospective liver transplant recipients. We further present the successful manufacture of the final drug product in the Biomedical Research Centre Clinical Research Facility (BRC CRF) at Guy's Hospital (King's College London) as a prelude for ThRIL.

\section{RESULTS}

\section{Isolation and expansion of a pure Treg population from ARC patients}

In preparation for ThRIL, clinical grade autologous Tregs were isolated from 9 patients with alcohol related cirrhosis (ARC), awaiting transplantation, and 9 age and sex matched healthy controls (HCs). Using a protocol previously reported [17], similar numbers of cells were isolated from ARC patients and $\mathrm{HCs}\left(7.14 \times 10^{6} \pm 0.938\right.$ vs. $7.91 \times 10^{6} \pm 0.728$, respectively; $P=0.528$ ) (Figure 1A). This result confirms the similar frequency of Tregs observed ex vivo in the blood of ARC patients and HCs $(4.13 \pm 0.932$ compared with $4.31 \pm 0.889$, respectively; $P$ $=0.888)$ (Figure 1B).

The feasibility of autologous $\mathrm{T}$ cell therapy depends on success in the expansion of sufficient cell numbers in vitro. In this regard, Tregs were expanded using anti-CD3/ CD28 monoclonal antibody-coated beads, high dose IL-2 and rapamycin, as previously reported $[17,18]$.

Assessment of the percentages of cells expressing $\mathrm{CD}^{+}, \mathrm{CD}^{+}$and $\mathrm{CD} 25^{+}$molecules, demonstrated on average a purity of $77.7 \% \pm 10.3 \mathrm{CD}^{+} \mathrm{CD} 25^{+}$and 2.50 $\% \pm 1.71 \mathrm{CD}^{+}$cells at the start of the culture (S1). Expansion in vitro under the conditions described led to an enrichment of $\mathrm{CD}^{+} \mathrm{CD} 25^{+}$cells; $91.3 \% \pm 2.33, P=$ 0.004 with only $0.153 \% \pm 0.073 ; P=0.008 \mathrm{CD}^{+}$cells at the end of culture (Figure 2A, 2B). The comparable purities of cells cultured in the absence of rapamycin were $87.5 \% \pm 4.12 ; P=0.088$ and $0.292 \% \pm 0.172 ; P=0.0019$, respectively.

In line with previous reports [19] the mean fluorescent intensity (MFI) of CD25 expression was highest following exposure of Tregs to rapamycin (data not shown).

\section{Tregs from ARC patients can be expanded to clinically suitable numbers}

We next determined whether patient-derived Tregs could be expanded in vitro to numbers required for the maximum dose of Treg injection planned for ThRIL $\left(4.5 \times 10^{6} / \mathrm{Kg}\right)$.

Tregs from both patients and $\mathrm{HCs}$ expanded rapidly with comparable fold-expansion during the 36 days of culture (in the presence of rapamycin: ARC $1430 \pm 239 v \mathrm{~s}$ $\mathrm{HC} 1060 \pm 139 ; P=0.207$, in the absence of rapamycin: $\mathrm{ARC} 2080 \pm 428$ vs $\mathrm{HC} 1670 \pm 359 ; P=0.469$ ) (Figure 2C). In addition, despite a trend for a reduced fold expansion there was no statistical difference in foldexpansion of Treg lines in the presence of rapamycin as compared to untreated cultures for both cohorts (ARC; 0 .199 , HC; $P=0.135$ ). Additionally the average expansion 
of the 9 different Treg lines in the presence of rapamycin was $1.07 \times 10^{9}$ cells \pm 0.085 (Figure 2D), demonstrating the feasibility of reaching numbers needed for the high dose of Tregs planned to be administered in ThRIL.

\section{Rapamycin expanded Tregs maintained high levels of FOXP3, CD127lo and CTLA4 with a sustained expression of CD62L and CXCR3}

Having established the enrichment of CD $4^{+} \mathrm{CD} 25^{+}$ Tregs under these culture conditions, the expression of the transcription factor, FOXP3, of importance in Treg development and function was analysed [20]. Initially, upon isolation the total percentage of $\mathrm{CD}^{+} \mathrm{CD} 25^{+} \mathrm{FOXP} 3^{+}$ cells stood at $77.7 \% \pm 3.35$, and contrary to published data reporting a loss of FOXP3 expression with prolonged periods of culture [21], the data reported an increase in the purity of culture in the presence of rapamycin to $90.66 \%$ $\pm 2.19, P=0.0053$. (Figure $3 \mathrm{~A}$ ).

In addition, using a more stringent gating strategy whereby we were able to distinguish two distinct populations based on FOXP3 expression, termed FOXP $3^{\mathrm{Hi}}$ and FOXP3 $3^{\text {Int }}$ (Supplementary Figure 1) it was also shown that the percentage of $\mathrm{CD} 4{ }^{+} \mathrm{CD} 25^{+} \mathrm{FOXP} 3^{\mathrm{Hi}}$ cells was increased in culture in the presence of rapamycin (S1: $24.7 \% \pm 2.95$ vs. Final harvest: $63.4 \% \pm 4.23 ; P<$ 0.0001 ) as compared to the untreated cultures (Figure $3 \mathrm{~B}$ ). In agreement, the MFI of FOXP3 was higher following exposure to rapamycin as compared to untreated cultures and baseline (Figure 3C).

Additionally, several subsets of Tregs have been described to date with reports that $\mathrm{CD} 4^{+} \mathrm{CD} 25^{\text {hi }} \mathrm{FOXP} 3^{+}$ Tregs typically lack the expression of the interleukin (IL)-7 receptor alpha chain, CD127 [22]. The differential expression of CD127 has been used to denote an optimally pure population of Tregs that is inversely correlated with FOXP3 levels and the suppressive function of human $\mathrm{CD}^{+}$Tregs. In support of the increase in purity of the cultures in the presence of rapamycin, our data demonstrate an increase in the frequency of CD127lo in the rapamycin treated cultures as compared the untreated cultures $(P=<0.0001)$ (Figure 3D).

Constitutive high level of expression of CTLA-4 represents another well-documented trait of Tregs that has also been shown to contribute to their suppressive function [23-25]. Analysis of the cultures at final harvest revealed that rapamycin led to an increase in the percentage of

A

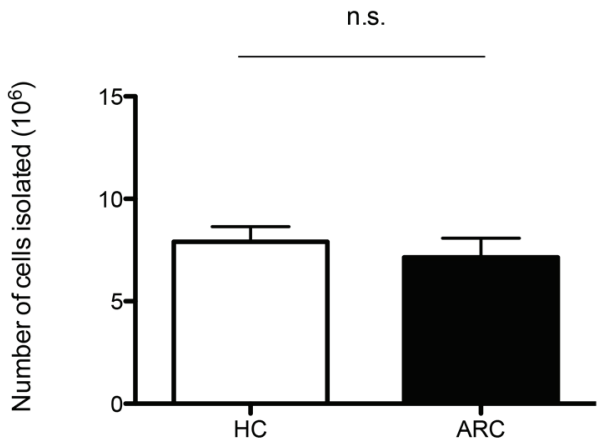

B
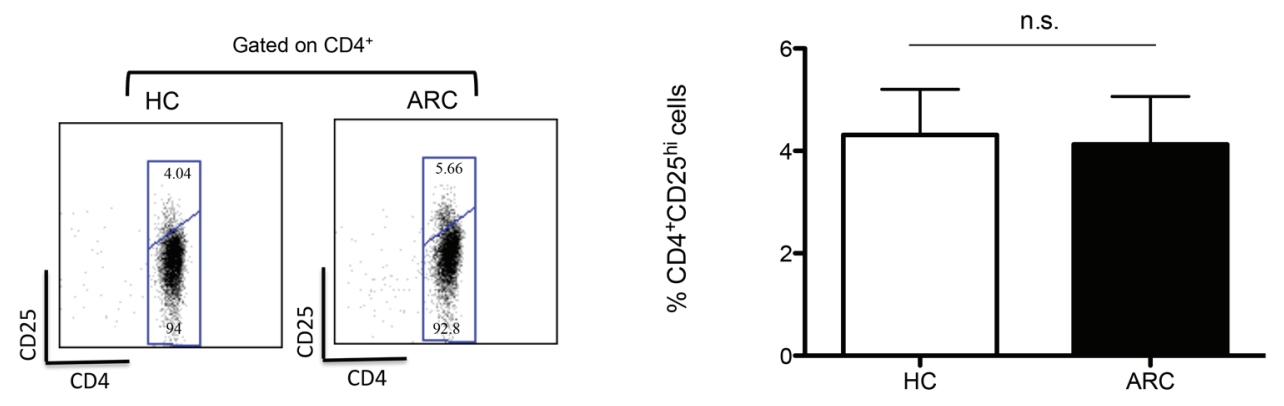

Figure 1: GMP Treg Isolation. A. Numbers of cells isolated from $150 \mathrm{ml}$ of blood by $\mathrm{CD} 8^{+}$cell depletion and CD25 cell enrichment compared between 9 ARC patients and 9 HCs. $* * * P<0.001$. B. Representative dot plot and graph denoting the circulating percentage of $\mathrm{CD} 4{ }^{+} \mathrm{CD} 25^{\mathrm{Hi}}$ Tregs of 5 ARC patients and 5 HCs. Abbreviation: n.s- not significant. Data are represented as mean +/- SEM. 
Tregs expressing CTLA-4 (S1: $15.3 \% \pm 2.51$ vs Final harvest: $70.6 \% \pm 4.522 ; P<0.0001)$ as compared to untreated cells (Final harvest: $14.6 \pm 4.15 ; P=0.859$ ) (Figure $3 \mathrm{~F}$ ) and this was mirrored by an increase in the
MFI of this marker in rapamycin treated cultures as compared to baseline (Figure 3G).

An additional consideration regarding Treg therapy is the site of action of Tregs and, consequently, the desired
A

Freshly isolated
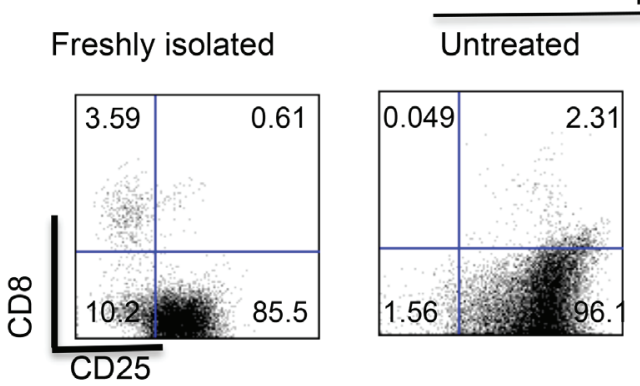

Final product

Rapamycin treated

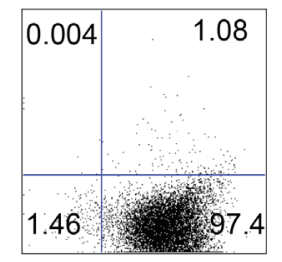

B

\section{Freshly isolated}

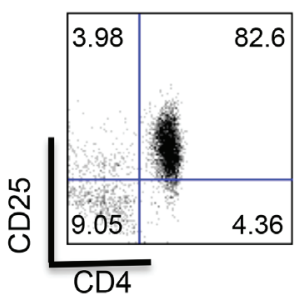

Final product

Untreated Rapamycin treated

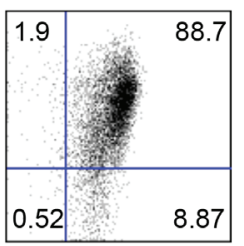

8.87

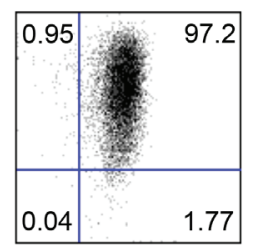

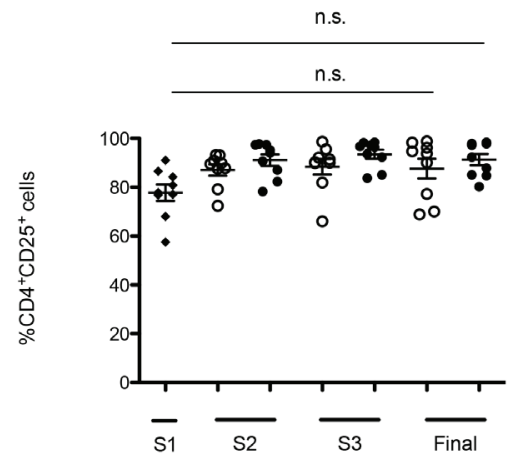

D
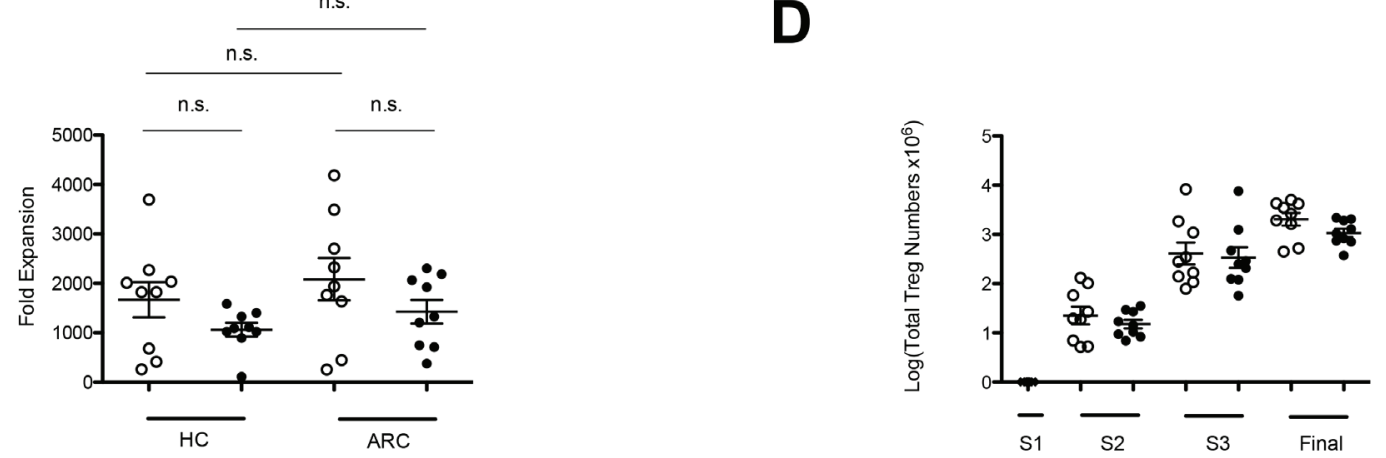

Figure 2: GMP Compatible Treg isolation and expansion. Two step strategy for Treg isolation: A. CD8 ${ }^{+}$cell depletion. B. $\mathrm{CD} 25^{+}$cell enrichment. In each case dots plots are representative of 9 ARC patients. Graphs denote the purity of the culture throughout the expansion period in both rapamycin and untreated cultures C. Tregs from ARC patients and HCs were expanded over 36 days \pm rapamycin. Fold expansion was calculated from Treg numbers at each stimulation. D. Predicted Treg numbers over the 36 day expansion period calculated based on fold expansion and the assumption that all cells were expanded at each stimulation. $n=9$ ARC, $n=9 H C s$. Abbreviation: S, stimulation; S1, day 0; S2, day 12; S3, day 24; final, day 36; n.s, not significant. ${ }^{* *} P<0.05,{ }^{* * *} P<0.001$. Data are represented as mean + - SEM. 
homing properties of the injected cells. In the transplant setting, Treg lymph node homing and their ability to traffic to the graft are both required for their protection against graft rejection [26]. In this regard, it was shown that culture of Tregs in the presence of rapamycin maintained their expression of the lymphoid homing receptor, $\mathrm{CD} 62 \mathrm{~L}$ (S1: $68.1 \% \pm 3.00 v s$. Final harvest: $72.0 \% \pm 3.51 ; P=$ 0.412 ), which was not preserved when cells were cultured in the absence of rapamycin; $P<0.0001$ (Figure 3H).

Furthermore, the expression of CXCR3, the chemokine receptor important for the migration and recruitment of Tregs to the liver was measured [27] at baseline and after the 36 days expansion. In the absence of rapamycin a decrease in the Tregs expressing CXCR3 $P=$
0.015 was observed. In contrast, the addition of rapamycin maintained the expression of this marker on the Tregs (Figure $3 \mathrm{H}$ ). Further analysis detailing the chemokine receptor expression of the final product and the cytokine production of the Tregs is presented in Supplementary Figures 2 and 3.

\section{Ex vivo expanded Tregs from ARC patients have increased suppressive ability}

To assess the functional properties of Tregs CFSE dilution assays were performed to evaluate the ability of freshly isolated and ex vivo expanded Tregs from patients

\section{A}
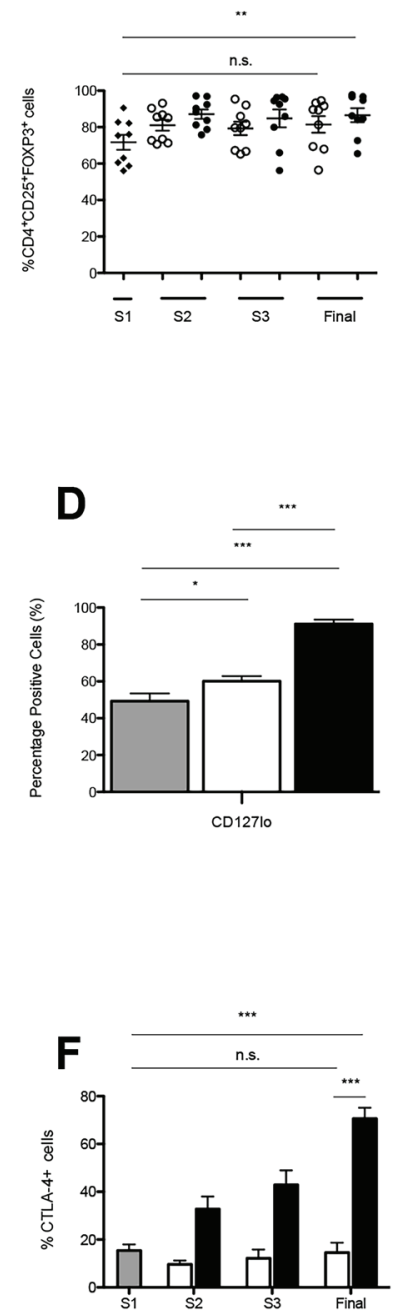

B

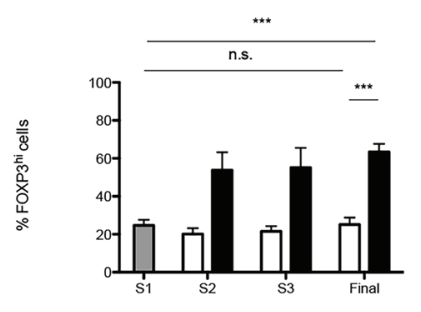

C

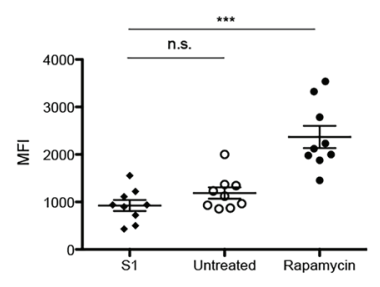

G

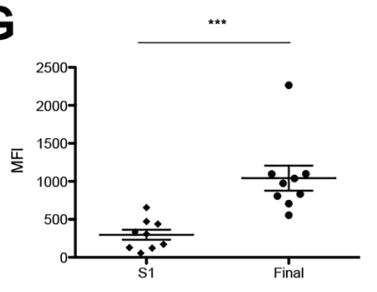

H

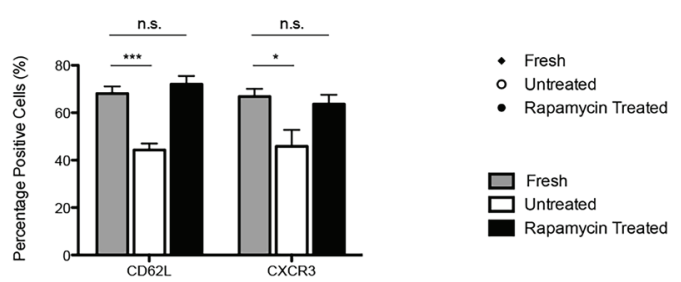

Figure 3: Expression of regulatory markers and homing receptor expression by Tregs throughout culture. A. Graph shows the mean percentage of $\mathrm{CD} 4{ }^{+} \mathrm{CD} 25^{+}$cells expressing $\mathrm{FOXP}^{+}$in both untreated and rapamycin treated cultures over 36 days of culture $\left(n=9\right.$ ARC). B. Graph shows the frequency of FOXP3 ${ }^{\mathrm{Hi}}$ Tregs, from 9 ARC patients, throughout culture \pm rapamycin. C. MFI of FOXP3 expression by Tregs. D. Graph shows the frequency CD127lo Tregs, from 9 ARC patients, throughout culture \pm rapamycin. E. Dot plot details the frequency of CTLA-4 expression on $\mathrm{CD} 4{ }^{+} \mathrm{CD} 25^{+}$Tregs from one representative sample. F. The graph depicts the frequency of CD4 ${ }^{+} \mathrm{CD} 25^{+} \mathrm{CTLA}-4^{+}$Tregs throughout culture \pm rapamycin. G. MFI of CTLA-4 expression at S1 and day 36 of culture \pm rapamycin. $\mathrm{H}$. Expression of CD62L and CXCR3 on $\mathrm{CD} 4{ }^{+} \mathrm{CD} 25^{+}$on day 0 and at day 36 Tregs cultured \pm rapamycin. Abbreviations: Mean fluorescent intensity (MFI) S- stimulation, n.s.-not significant. ${ }^{*} P<0.01,{ }^{*} * *<0.001$. Data are represented as mean $+/-$ SEM. $n=9$ ARC. 
to suppress the proliferation of T effectors (Figure 4).

The data clearly demonstrated that at the end of expansion, the suppressive function elicited by ARC Tregs in the presence of rapamycin was significantly higher as compared to freshly isolated Tregs at different Treg:Teffector ratios (1:1 ratio - final harvest: $84.8 \% \pm$ 3.96 vs. S1: $25.4 \% \pm 6.03 ; P=0.0001,1: 10$ ratio -final harvest: $68.3 \% \pm 6.85 v s$. S1: $16.2 \% \pm 4.68 ; P=0.0001)$. In the untreated cultures, despite an increase in Treg suppressive function at day $12(\mathrm{~S} 2)$, this increase did not reach similar levels to those obtained from Tregs expanded in the presence of rapamycin (1:1 ratio $60.5 \% \pm 7.26 \mathrm{vs}$. $88.2 \% \pm 2.76$, respectively; $P=0.0026$; and $1: 10$ ratio $42.0 \% \pm 8.99$ vs. $79.1 \% \pm 3.90$, respectively; $P=0.0016$ ). Moreover, the increase in Treg suppressive function was not preserved by final harvest in the untreated cultures as compared to the rapamycin treated cultures (1:1 ratio $25.2 \% \pm 4.58$ vs $84.8 \% \pm 3.96$, respectively; $P=0.0001$; $1: 10$ ratio $7.32 \% \pm 2.32$ vs $68.3 \pm 6.85$, respectively; $P=$ 0.0001 ) (Figure 4). These results further support the use of the rapamycin based GMP protocol in the expansion of autologous Tregs from ARC patients in view of the increased Treg suppressor function.

\section{Rapamycin stabilizes the Treg population by preventing IL-17 production}

One of the major concerns in Treg immunotherapy is the plasticity of Tregs and their conversion to cells producing inflammatory cytokines, when exposed to a pro-inflammatory environment $[28,29]$. As such, freshly isolated and expanded Tregs were cultured for 5 days in the presence of Th17 skewing conditions and the percentage of IL- $17^{+}$cells (Figure $5 \mathrm{~A}$ ) and the production of IL-17 (Figure 5B) assessed by FACS and ELISA, respectively, in order to ascertain their stability. Our data clearly confirmed that over the 36-days culture period the presence of rapamycin resulted in the production of a stable population of Tregs with a reduced percentage of IL- $17^{+}$cells as compared to baseline, when exposed to a proinflammatory milieu (Mix 1: $P=0.0384$; Mix 2: $P=$ $0.0446)$. Additionally, diminished IL-17 production was detected on analysis of culture supernatants, confirming the data obtained by intracellular staining (Mix 1: S1 $1965 \mathrm{pg} / \mathrm{ml} \pm 318 v s$. final harvest $124 \mathrm{pg} / \mathrm{ml} \pm 34.5 ; P<$ 0.0001 ; Mix 2: S1 1322pg/ml $\pm 347 v s$. rapamycin at final harvest: $84.3 \mathrm{pg} / \mathrm{ml} \pm 35.3 ; P=0.0027$ ) (Figure 5A, 5B). Moreover, assessment of the percentage of IFN $\gamma^{+}$cells also clearly demonstrated that rapamycin resulted in a non-inflammatory Treg population with a reduction in the frequency of FOXP ${ }^{+}$IFN $\gamma^{+}$cells by final harvest (Mix 1 $\mathrm{S} 1 ; 6.42 \% \pm 0.915$ vs. final harvest $2.54 \% \pm 0.560 ; P=$ 0.0023 ; Mix 2; S1 4.61\% \pm 0.698 vs. final harvest 2.82\%

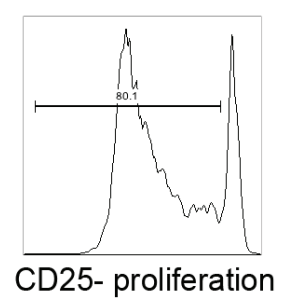

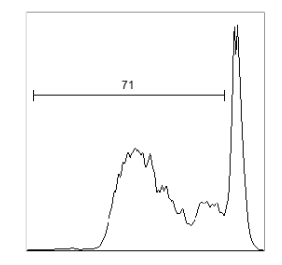

S1

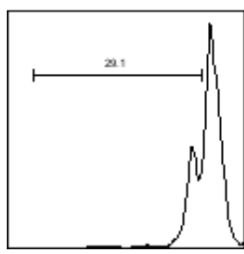

Rapamycin Treated (Final Product)
- Fresh

- Untreated

- Rapamycin Treated
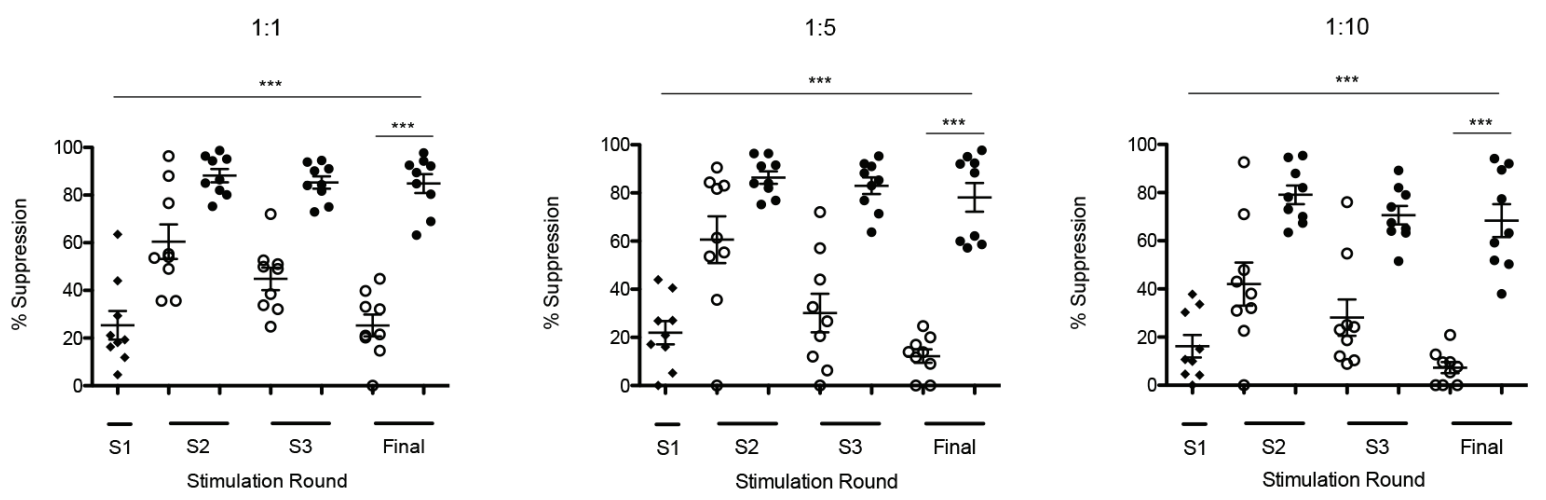

Figure 4: Assessement of Treg suppressive function. Representative histogram and graph from 9 ARC patients upon assessment of Treg suppressor function. The suppressive function of Tregs cultured \pm rapamycin was assesed by CFSE dilution assay at day 0 and throughout the 36 day culture period. n.s.- not significant. $* P<0.05, * * * P<0.001$. Data are represented as mean $+/$ - SEM. 
$\pm 0.688 ; P=0.084$ ) (Figure 5C).

To further assess the susceptibility of Tregs to differentiate into Th17 cells the expression of CD161 on the Tregs was investigated. Expression of CD161 by $\mathrm{T}$ cells has been reported as a marker for precursors of IL-17 producing T cells and in addition, characterises a population of Tregs with the propensity to produce IL-17, as shown by our group and others [30-33].

Our data showed that during the 36-day expansion period there was a decrease in the percentage of $\mathrm{CD} 161^{+}$Tregs (from $19.6 \% \pm 2.42$ to $1.48 \% \pm 0.26$; $P<0.0001$ ) (Figure 5D). In parallel a decrease in the

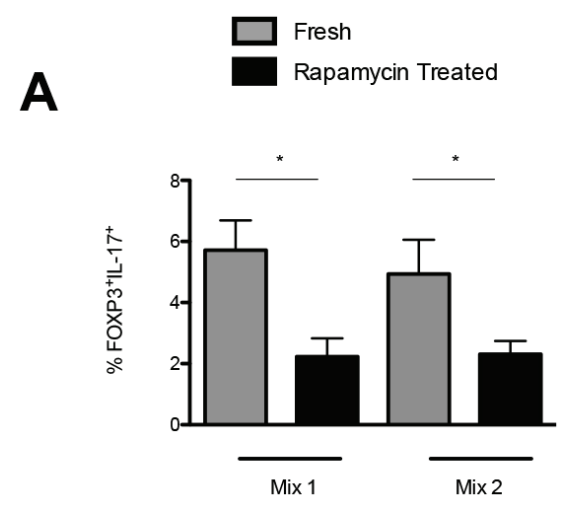

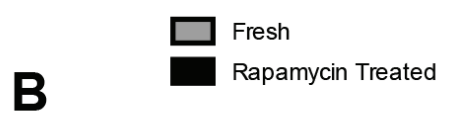

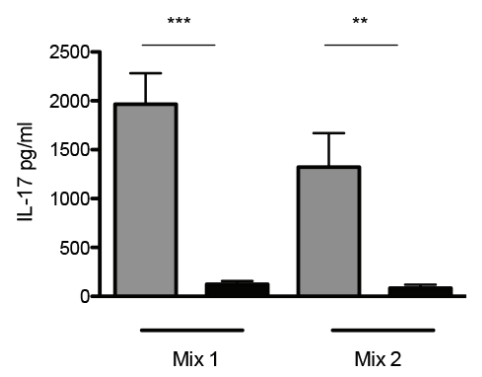

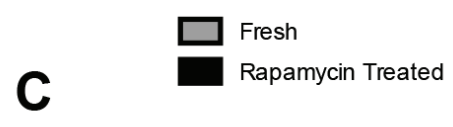

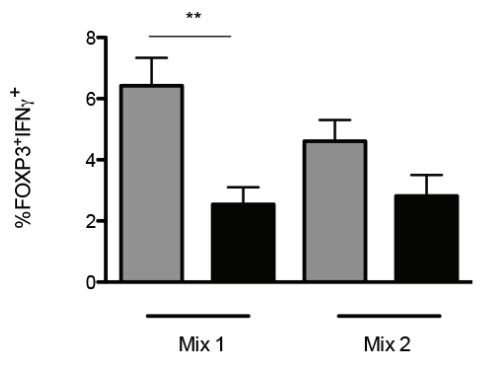

\section{D}
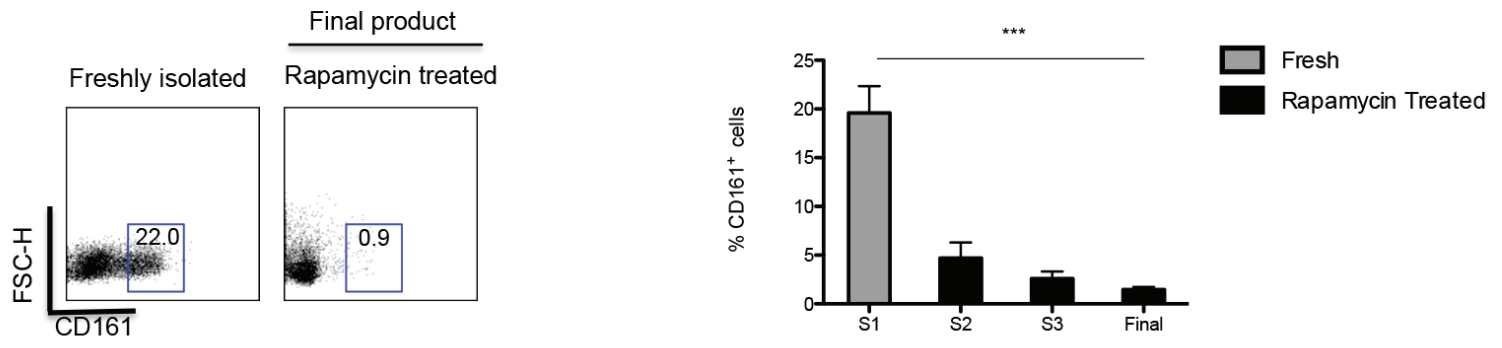

\section{$\mathbf{E}$}
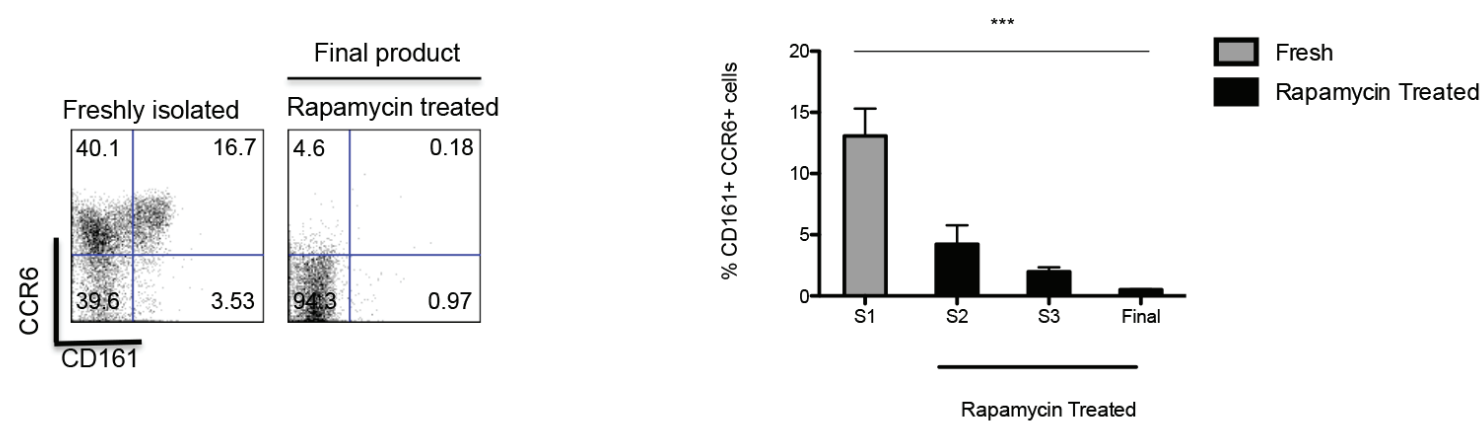

Figure 5: Intracellular expression of IL-17 and IFN- $\gamma$ and production of IL-17 by ex vivo expanded Tregs. A. Frequency of $\mathrm{IL}_{-1}-17^{+}$in $\mathrm{CD}_{4}{ }^{+} \mathrm{CD} 25^{+} \mathrm{FOXP3}{ }^{+}$Tregs upon isolation and post culture in the presence of rapamycin (day 36) when exposed to two separate mixes of pro-inflammatory cytokines (Mix 1: IL-2, IL1 $\beta$, IL-6 and TGF- $\beta$ and Mix 2: IL-2, IL-21, IL-23 and TGF-). B. IL-17 (pg/ml) concentration in a 5-day culture supernatant of the rapamycin expanded Tregs in the presence of Mix1 and Mix2. C. Frequency of IFN- $\gamma^{+}$ in $\mathrm{CD}_{4}^{+} \mathrm{CD} 25^{+} \mathrm{FOXP}^{+}$Tregs upon isolation and post ex vivo expansion in the presence of rapamycin (day 36) when exposed to Mix 1 and Mix 2. D. Gating strategy and Frequency of $\mathrm{CD} 161^{+}$Tregs throughout culture. Dot plot depicts expression of $\mathrm{CD} 161$ on $\mathrm{CD} 4{ }^{+} \mathrm{CD} 25^{+}$Tregs from a representative sample of 9 ARC patients. Graph shows the dynamics of CD161 expressing Tregs throughout culture. E. Gating strategy and Frequency of $\mathrm{CCR} 6{ }^{+} \mathrm{CD} 161^{+}$Tregs throughout culture. Dot plot of $\mathrm{CD} 161^{+} \mathrm{CCR} 6^{+}$co-expression on $\mathrm{CD} 4^{+} \mathrm{CD} 25^{+}$Tregs from a representative sample of $9 \mathrm{ARC}$ patients and graph of percentage $\mathrm{CD} 161^{+} \mathrm{CCR} 6^{+}$co-expression throughout culture. n.s.-not significant. ${ }^{*} P$ $<0.05,{ }^{*} P<0.01$. ${ }^{* * *} P<0.001 . n=9$ ARC patients. Data are represented as mean $+/-$ SEM. 
Table 1A: Clinical-grade Tregs expanded in the Clinical Research Facility

\begin{tabular}{|l|l|l|l|l|}
\hline & \multicolumn{4}{|c|}{ Total cells x10 } \\
\hline & S1 & S2 & S3 & Final harvest \\
\hline ARC 1 & 1.47 & 28 & 172 & 680 \\
\hline ARC 2 & 4 & 17.7 & 159 & 1250 \\
\hline ARC 3 & 5.5 & 41.3 & 397.6 & 2680 \\
\hline
\end{tabular}

All final products reached above the numbers needed for the maximum dose of Treg injection planned $\left(4.5 \times 10^{6}\right)$ for the ThRIL trial; $n=3$. Abbreviation: $\mathrm{S}$, stimulation; $\mathrm{S} 1$, day 0 ; $\mathrm{S} 2$, day 12 ; S3, day 24; final, day 36

Table 1B: Treg manufacture in the Clinical Research Facility

\begin{tabular}{|c|c|c|c|c|c|c|c|}
\hline \multirow[t]{2}{*}{ Test } & \multirow{2}{*}{ Specification } & \multicolumn{2}{|l|}{ ARC 1} & \multicolumn{2}{|l|}{ ARC 2} & \multicolumn{2}{|l|}{ ARC 3} \\
\hline & & $\begin{array}{l}\text { Final } \\
\text { harvest }\end{array}$ & Defrosting & $\begin{array}{l}\text { Final } \\
\text { harvest }\end{array}$ & Defrosting & $\begin{array}{l}\text { Final } \\
\text { harvest }\end{array}$ & Defrosting \\
\hline \multicolumn{2}{|c|}{ Months post cryopreservation } & & 3 & & 3 & & 3 \\
\hline Identity: & \begin{tabular}{|lll} 
Positive for CD4 \\
CD25 & & \\
FOXP3 & & \\
\end{tabular} & YES & YES & YES & YES & YES & YES \\
\hline Purity: & $\begin{array}{l}\geq 60 \% \text { of entire cell } \\
\text { population CD4 } \\
\text { CD25 } 4^{+} \text {FOXP3 }\end{array}$ & 93.9 & 89.1 & 88.8 & 92.6 & 84.9 & 97.0 \\
\hline \multirow[b]{2}{*}{ Impurity: } & $\leq 10 \% \mathrm{CD} 8$ & 0.36 & 1.14 & 0.43 & 0.5 & 1.95 & 0.6 \\
\hline & $\begin{array}{l}\leq 100 \text { beads per } \\
3 \times 10^{6} \text { cells }\end{array}$ & 75 & - & 23 & - & 45 & - \\
\hline Viability: & $\geq 70 \%$ viability & 91.0 & 93 & 97.3 & 85.0 & 96.5 & 84.0 \\
\hline $\begin{array}{l}\text { Recovery } \\
\text { (live): }\end{array}$ & $\geq 70 \%$ & - & 95 & - & 80.0 & - & 114 \\
\hline Potency: & $\geq 60 \%$ suppression & 93.0 & 99 & 65.0 & 97.0 & - & 95.0 \\
\hline \multirow{3}{*}{ Safety tests: } & Sterility-no growth & No growth & - & No growth & - & No growth & - \\
\hline & $\begin{array}{l}\text { Endotoxin } \leq 175 \mathrm{IU} / \\
\mathrm{mL}\end{array}$ & $<5 \mathrm{IUU} / \mathrm{ml}$ & - & $<5 \mathrm{IU} / \mathrm{ml}$ & - & & - \\
\hline & $\begin{array}{l}\text { Mycoplasma-not } \\
\text { detected }\end{array}$ & not detected & - & not detected & - & & - \\
\hline
\end{tabular}

All final products met the necessary release criteria on day 36 for their clinical application. After 3 months post cryopreservation cells maintained their phenotype and suppressive function.

Abbreviation: ARC, alcohol related cirrhosis 
percentage of Tregs co-expressing CD161 and CCR6 in rapamycin treated cultures as compared to baseline was also demonstrated $(0.500 \pm 0.107$ vs $12.5 \% \pm 1.75$, respectively, $P<0.0001$ ) (Figure 5E).

\section{Tregs from ARC patients were enriched, expanded and cryopreserved in the Clinical Research Facility}

To extend the Treg protocol from the laboratory to the GMP facility and validate the process for clinical use in ThRIL, $150 \mathrm{ml}$ of peripheral blood was obtained from three patients with ARC and Tregs isolated, using the CliniMACS Plus system and expanded in the BRC CRF, Guy's Hospital. Comparison of the recovery of the isolated cells from ARC patients in the BRC CRF and the research laboratory revealed an initial lower recovery of cells, $3.68 \pm 1.18 \times 10^{6}$ vs. $7.14 \times 10^{6} \pm 1.27$, respectively (Figure 1A, Table 1A). Despite this, Tregs from patients were successfully expanded, reaching numbers well over the requirements of the ThRIL trial (Table 1A).

After ex vivo expansion, a comprehensive analysis of the Tregs was performed to ensure the final product satisfied the specified release criteria, essential for their clinical application (Supplementary Table 4). At final harvest the mean percentage of cells with a $\mathrm{CD}^{+} \mathrm{CD}_{25} 5^{+} \mathrm{FOXP}^{+}$phenotype was $89.2 \% \pm 2.61$ with $0.913 \% \pm 0.591 \mathrm{CD}^{+}$cells, with a mean viability of $94.9 \% \pm 1.98$. Evaluation of the potency of the final product showed the expansion of Tregs with suppressive ability $>65 \%$ (Table $1 \mathrm{~B}$ ).

Of note, however, ThRIL requires the final product to be injected 3 months post transplantation and therefore necessitates cryopreservation of these cells. Following cryopreservation $>80 \%$ live cells were recovered and the results demonstrate that Tregs maintained their phenotype and function (Table 1B).

\section{DISCUSSION}

One of the major drawbacks following liver transplantation is the requirement for lifelong treatment with immunosuppressants with their accompanying side effects and complications. This contributes to a disappointing $60 \%$ patient survival rate at 10 years after transplantation. In this regard, the use of cell-based therapies, harnessing the natural immunoregulatory properties of the immune system, is an emerging therapeutic option and Tregs have been recognized as ideal candidates in this endeavor.

ThRIL is a pioneering two stage clinical trial investigating the use of autologous Treg immunotherapy as an individualised medicine to promote transplantation tolerance in liver transplantation. Stage I, prioritises the safety and tolerability of Treg immunotherapy with Treg efficacy assessed in Stage II whereby immunosuppression withdrawal will be attempted in transplant recipients who have received the highest tolerated dose of Tregs.

To date studies aimed at withdrawing immunosuppression in liver transplant recipients early post transplantation have been largely unsuccessful [34] highlighting the need for an intervention, such as that proposed in ThRIL, to promote 'tolerance'.

Here, we outline the first account of the ex vivo expansion of Tregs from prospective liver transplant recipients at GMP standards. The data presented describes the clinical grade isolation strategy and demonstrates the feasibility of autologous Treg cell-based therapy in liver transplantation.

We present data on the selection of a pure population of Tregs $\left(\mathrm{CD}^{+} \mathrm{CD} 25^{+}\right.$at $\left.\mathrm{S} 1: 77.7 \% \pm 10.3\right)$, using a twostep magnetic activated cell sorting (MACS) protocol. In two of the reported clinical trials $[13,16]$ a higher degree of Treg purity was attained using Treg isolation based on the combined expression of $\mathrm{CD} 4^{+}, \mathrm{CD} 25^{+}$, and low expression of CD127 molecules [22]. Whilst cell isolation based on a combination of these markers is highly effective, the lack of GMP cell sorter facilities in the UK makes this translationally unfeasible. In addition, Marek et al. showed that during the expansion process Tregs were "transforming" into effector/memory like cells and proposed that regardless of the phenotypic markers used for Treg isolation, the only variable to maintain Treg phenotype and function is to limit the duration of expansion to 2 weeks [35].

In support of this study, others have also shown that the large-scale manufacture of Tregs remains challenging, reporting that even when starting with a highly pure population of Tregs, repeated stimulation results in the loss of FOXP3 expression [21]. In the clinical trial conducted by Trzonkowski et al. a decrease in the percentage $\mathrm{FOXP}^{+}$cells after successive weekly stimulation was reported [13]. However, the disadvantage of limiting cultures to two rounds of stimulation became evident in the trial of Treg immunotherapy in Type 1 diabetes where the authors noted an insufficient Treg yield in four out of the ten patients [16].

We generated Tregs in concordance with the proposed GMP protocol, expanding these cells in vitro for 36 days with three rounds of stimulation, in the presence of rapamycin. This resulted in the expansion of Tregs to numbers sufficient for administration of the maximum dose for the ThRIL trial. Despite the three rounds of stimulation, and contrary to the studies outlined above, FOXP3 expression was maintained in culture and the data clearly demonstrated that in the presence of rapamycin there was an increase in the percentage of FOXP $3^{\mathrm{Hi}}$ Tregs and in the level of expression of FOXP3 at final harvest (Figure 3B, 3C).

One of the concerns with the clinical translation of bead-separated Treg preparations is the presence 
of 'contaminating' effector T cells. However, as has been reported previously [18], expansion of Tregs in the presence of rapamycin led to the enrichment of a Treg population with increased CD127lo and CTLA4 expression (Figure 3D, 3F), correlating with the pronounced increase in suppressive function (Figure 4). CTLA-4 has been recognized as an important regulatory marker expressed by Tregs and has been reported to play an important role in their suppressive function, through the internalization of co-stimulatory molecules on antigen presenting cells (APC) [23]. This has significant implications, concerning the clinical application of autologous patient derived Tregs in the setting of liver transplantation, whereby our protocol ensures the high expression of this key regulatory molecule.

Another major potential barrier to Treg therapy is the possibility that these cells may assume a pro-inflammatory phenotype. In this study, we provide further evidence to our published data where we report that conditioning of Tregs with rapamycin leads to the production of a stable, non-inflammatory Treg population due to the inhibition of IL-17 and IFN- $\gamma$ production by Tregs in vitro in the presence of intense inflammatory conditions (Figure 5A, 5B) $[18,36]$.

In line with this, a decrease in the percentage of cells co-expressing CD161 and CCR6 was demonstrated, confirming previous work [37]. Moreover, in view of the plasticity of Tregs, Kopft et al. studied the reciprocal differentiation of Tregs and Th17 cells and reported that rapamycin suppresses the differentiation of pathogenic Th17 cells [38]. As such, patients in the ThRIL study will be taking rapamycin by the time of Treg infusion. This adjunctive immunosuppression has the dual advantages of promoting Treg survival and stability by reducing the risk of the injected cells acquiring pro-inflammatory features.

Furthermore there have been reports of the importance of epigenetic control of Foxp3 expression through the methylation of the Treg specific demethylated region (TSDR). Future research will be focused at understanding Treg commitment and epigenetic regulation of FOXP3 expression so that the mechanisms can be harnessed to stabilise the Tregs, of importance for their clinical application.

In addition to stability, therapeutic strategies using Tregs have to also take into account the need for appropriate tissue trafficking to enable contact with their target cells. The expression of the chemokine receptor, CXCR3, has been reported to mark subsets of $\mathrm{T}$ cells associated their migration to sites of inflammation [39]. Furthermore, in a murine model of $\mathrm{T}$ cell mediated liver injury, Lapierre et al. demonstrated the ability of CXCR3 ${ }^{+}$ Tregs to migrate to the liver, in turn potentiating the effectiveness of Treg adoptive transfer [40]. The data presented here demonstrates the preservation of cells expressing CD62L and CXCR3, important for their passage to lymph nodes and the liver respectively (Figure
$3 \mathrm{H})$.

Finally, we show that despite a lower recovery of isolated cells (Tables 1A \& 1B), partly explained by the closed system of isolation procedure which involves a longer, more vigorous cell isolation procedure, adequate numbers of Tregs, that meet the trial release criteria, can be expanded in the BRC CRF at Guy's Hospital and remain functional after freeze-thawing, a prerequisite precluding their clinical translation.

Additionally, it is pertinent to note that initial confidence in adoptive Treg cell therapy as a self-sufficient entity, experimental data has shown that the efficacy of Treg therapy requires the setting of a favorable in vivo environment, supporting both the cell engraftment and the chance of inducing tolerance, such as transient host $\mathrm{T}$ cell depletion by immunosuppressive treatments $[41,42]$. This highlights the importance of strategies to tailor immunosuppressive therapy to ensure the in vivo survival of the injected Tregs or enhance their longevity in vivo. In this regard the clinical protocol for ThRIL is based on a Treg supportive immunosuppressive regimen including the use anti-thymocyte globulin (ATG), to induce lymphopenia with a preferential preservation of Tregs [43]. Additionally to limit memory $T$ cell expansion post ATG induction, patients are started on tacrolimus and prednisolone and a month prior Treg infusion maintained on low dose tacrolimus with the addition of rapamycin, to promote selective Treg expansion in vivo [44]. The intention behind this protocol: to create a tolerogenic milieu thus maximizing the potential efficacy of the exogenously administered Tregs through prolongation of their in vivo survival. It is also reassuring that these cells will be injected in a 'Treg nurturing' environment, centered on the inclusion of rapamycin, as compared to other immunosuppressants whose indiscriminant mechanism of action poses a threat to Treg survival.

Thus, tailoring the immunosuppressive regimen along with the administration of ex vivo expanded Tregs may potentially maintain post liver transplant tolerance, accomplishing the ultimate aim of Treg immunotherapy trials in this setting.

Presently, the first two patient recruited into the ThRIL trial have received the first Treg injection, with no reported toxicity to date. The near future will now see the reporting of this clinical trial along with the much anticipated immunomontoring data, informing the in vivo dynamics of the cells expanded. There is no question that the information gleaned from the ThRIL trial will serve as to guide the transition of Tregs as a viable therapeutic option in liver transplant recipients.

Additionally, with the advent of GMP-compliant FACS sorting there will be developments in the current GMP protocol for the manufacture of the final cell product with a focus on the optimal Treg subset with potent suppressive function, specificity, and those that are epigenetically stable. 


\section{MATERIAL AND METHODS}

\section{Participant selection criteria}

$150 \mathrm{ml}$ of peripheral blood was obtained from 12 patients with alcohol related cirrhosis (ARC), awaiting transplantation. Patient selection was based on the inclusion criteria in accordance with the ThRIL clinical protocol (NCT02166177) (Supplementary Table 1 and Table 2). As outlined by the UK transplant registry http://www.odt.nhs.uk/uk-transplant-registry/ cirrhosis secondary to alcohol is one of the leading indications for liver transplantation in the UK and as such this cohort of patients form the majority of patients recruited into the ThRIL trial.

Peripheral blood was obtained from 9 age and sex matched healthy controls (HCs). All blood samples were handled and disposed of in concordance with Human Tissue Act 2008. Human studies were conducted in accordance with the Declaration of Helsinki and approved by the Institutional Review Board (09/H0707/86).

\section{Treg isolation}

In the laboratory, peripheral blood mononuclear cells (PBMC) were isolated from patients and HCs by lymphocyte (PAA, Pasching, Austria) density gradient centrifugation and depleted for $\mathrm{CD} 8^{+}$cells followed by enrichment of $\mathrm{CD} 25^{+} \mathrm{T}$ cells using magnetic beads (Miltenyi Biotec, Woking, UK) and as previously reported [17]. All reagents and consumables used were of clinical GMP grade.

In the BRC CRF, blood volume was reduced, using the $\operatorname{Sepax}^{\circledR} 2$ device (Biosafe) prior to Treg isolation. Tregs were purified using a combination of $\mathrm{CD} 8^{+}$ reduction (CliniMACS CD8 reagent, Miltenyi Biotec, Woking, UK) and enrichment steps for $\mathrm{CD}_{2} 5^{+}$cells (CliniMACS CD25 reagent, Miltenyi Biotec), using the automated CliniMACS ${ }^{\circledR}$ Plus System (Miltenyi Biotec) in the BRC CRF at Guy's Hospital. All processing steps were performed in closed systems, using single use tubing sets.

\section{Expansion of Treg lines}

Isolated cells were plated at $1 \times 10^{6} / \mathrm{ml}$ cell and activated with anti-CD3/CD28 coated beads (Invitrogen, Paisley, UK; Miltenyi Biotech) at a 2:1 bead:cell ratio. Cells were expanded in culture media X-vivo 15 (Lonza, Basel, Switzerland) 5\% human AB serum (HS) (Biosera, Ringer, UK; Lonza) containing rapamycin $(100 \mathrm{nM})$ (Rapamune $^{\circledR}$, Wyeth, USA) for 36 days. IL-2 (500 IU/ $\mathrm{ml}$, Proleukin ${ }^{\circledR}$, Novartis, UK) was added at day 4 postactivation and replenished every 2 days. Cells were restimulated every 10-12 days. Beads were magnetically removed and the cells washed in PBS. This process was repeated to ensure bead removal following which, fresh beads, rapamycin and IL-2 were added. Expanded cells were used for further analysis at each time of restimulation up until day 36 of expansion.

In the BRC CRF, under GMP conditions, enriched cells were seeded in MACS $^{\circledR}$ GMP Cell Expansion Bags at $0.5 \times 10^{6}$ cells $/ \mathrm{mL}$ in TexMACS ${ }^{\text {TM }}$ GMP Medium (Miltenyi Biotec) supplemented with 5\% human $\mathrm{AB}$ serum (Seralab, UK), containing $100 \mathrm{nM}$ rapamycin (Rapamune ${ }^{\circledR}$, Pfizer) and activated with anti-CD3/CD28coated beads (4:1 bead:cell ratio, MACS GMP ExpAct Treg Kit, Miltenyi Biotec). Human recombinant IL-2 (500 $\mathrm{IU} / \mathrm{mL}$; Proleukin ${ }^{\circledR}$, Novartis) was added at day 4-6 and replenished every 2-3 days. The cells were rested 4 days before restimulation. Stimulation occurred on days 12 and 24 , during which time cells were pooled, fresh beads (1:1), rapamycin, and IL-2 added. At final harvest, the pooled cells were processed on the CliniMACS Plus Instrument using a pre-set depletion program to remove the ExpAct Treg expansion beads. A sample of the cells was assessed for safety and functional analysis.

\section{Flow cytometry}

Flow cytometric analysis was performed on freshly isolated and expanded Tregs using the BD FACSCanto ${ }^{\mathrm{TM}}$ cell analyzer (BD Bioscience, Oxford, UK) and analysed using FlowJo software (TreeStarInc, OR, USA). In short, cells were washed and stained with the listed mAbs in the Supplementary Table 3 for $30 \mathrm{~min}$ at $4^{\circ} \mathrm{C}$. Appropriate isotype control antibodies were used for each sample. Following staining, cells were examined by flow cytometry.

Intracellular staining for FOXP3 was performed in accordance with the manufacturer's protocol (eBioscience). Expression levels of and IL-17 was assessed after activation of cells with phorbol myristate acetate (PMA, 5ng/ml, Sigma Aldrich, St Luis, MO, USA), Ionomycin ( $1 \mu \mathrm{g} / \mathrm{ml}$, Sigma Aldrich, St Luis, MO, USA) and Monensin ( $2 \mu \mathrm{M}$, eBioscience, San Diego, CA, USA) for 4 hours. Subsequently, the intracellular staining for IL-17 was performed according to the manufacturer's protocol.

In the BRC CRF, flow cytometry, using CD4-PerCP/ Cy ${ }^{\mathrm{TM}}$ 5.5, CD-25PE, CD8-APC was carried out on the BD FACSCanto ${ }^{\mathrm{TM}}$ cell analyzer (BD Bioscience). Intracellular staining for FOXP3-FITC was performed, as above, in accordance with manufacturer's protocol (eBioscience). Appropriate isotype controls and Fluorescence minus one controls were used to assign gates and analysis carried out, using the FlowJo software. 


\section{Suppression assay}

Responder $\mathrm{CD}^{+} \mathrm{CD} 25^{-} \mathrm{T}$ cells were obtained from PBMCs by negative selection using unconjugated anti-

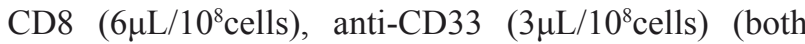
Caltag, California, USA), anti-CD14 ( $7 \mu \mathrm{L} / 10^{8}$ cells), antiCD16 ( $7 \mu \mathrm{L} / 10^{8}$ cells), anti-CD19 $\left(6 \mu \mathrm{L} / 10^{8}\right.$ cells $)$, antiCD56 $\left(3 \mu \mathrm{L} / 10^{8}\right.$ cells $)$, anti- $\gamma \delta$ TCR $\left(7 \mu \mathrm{L} / 10^{8}\right.$ cells $)$ and glycophorin CD235a (all Diaclone, Gen-probe, San Diego, USA) antibodies with pan-IgG microbeads and anti-CD25 microbeads (both Invitrogen, Paisley, UK)

Aliquots of the $\mathrm{CD} 4{ }^{+} \mathrm{CD} 25$ - cells were cryopreserved and used as allogeneic responder cells in suppression assays.

Cryopreserved responder $\mathrm{CD}^{+} \mathrm{CD} 25^{-} \mathrm{T}$ cells (Teff) were thawed and labelled with $2.5 \mathrm{nM}$ the carboxyfluorescein succinimidyl ester (CFSE) (Molecular Probes, Carlsbad, CA, USA). Responder purity was $>95 \%$ (Supplementary Figure 4). 1x10\%/well of responder T cells were co-cultured at different ratios (Treg: Teff $=1: 1,1: 5$ and 1:10) with Tregs in X-Vivo 15 medium supplemented with 5\% HS and activated by anti-CD3/CD28-coated beads (Invitrogen, Paisley, UK) in U-bottom 96-well plates. Cells were incubated at $37^{\circ} \mathrm{C}, 5 \% \mathrm{CO}_{2}$ for 5 days. After harvest, proliferation of CFSE-labelled responder cells was determined by flow cytometry (FACSCalibur or on LSRFortessa ${ }^{\mathrm{TM}}$ cell analyzer (BD Bioscience) and analyzed with FlowJo software (Tree Star Inc, OR, USA). The suppressive ability of Treg lines was assessed as the percentage decrease of Teff proliferation in the presence of Tregs. The calculation was based on the proliferation of responder $\mathrm{T}$ cells alone compared with the proliferation of cultures also containing Treg cells.

\section{Treg culture in the presence of pro-inflammatory cytokines}

Freshly isolated, untreated and rapamycin treated $\mathrm{CD} 4{ }^{+} \mathrm{CD} 25^{+} \mathrm{T}$ cells $\left(5 \times 10^{5}\right)$ were activated with anti-CD3/ CD28 coated beads at 1:1 bead:cell ratio and cultured for 5 days in the presence of pro-inflammatory cytokine cocktails: Mix 1: IL-2 (10 IU/ml), IL1 $\beta(10 \mathrm{ng} / \mathrm{ml}, \mathrm{R} \& D$ Systems, Minneapolis, MN, USA), IL-6 (4ng/ml, R\&D Systems, Minneapolis, MN, USA) and TGF- $\beta(5 \mathrm{ng} / \mathrm{ml}$, R\&D Systems, Minneapolis, MN, USA). Mix 2: IL-2 (10 IU/ml), IL-21 (25ng/ml, Cell Sciences, Canton, MA, USA), IL-23 (25ng/ml, R\&D Systems, Minneapolis, MN, USA) and TGF- $\beta$ ( $5 \mathrm{ng} / \mathrm{ml}$, R\&D Systems, Minneapolis, MN, USA). Cells cultured in complete medium supplemented with IL-2 $(10 \mathrm{IU} / \mathrm{ml})$ were used as controls to ensure their survival throughout the 5-day stability assay.

At the end of the culture cells were harvested, activation beads removed by magnetic adherence and analysed for IL-17 and IFN- $\gamma$ expression by intracellular staining. IL-17 in supernatants was analysed by an indirect sandwich ELISA.

\section{ELISA}

ELISA for human IL-17 was carried out using the Duo-Set ELISA kit from R\&D (Abingdon, UK) according to manufacturer's instructions

\section{Cryopreservation of the expanded Tregs in the CRF}

After final harvest, all batches were assessed against the set release criteria for the ThRIL trial (Supplementary Table 4) and subsequently cryopreserved. In brief, Treg numbers equivalent to doses for the ThRIL trial were resuspended in $2.1 \mathrm{ml}$ of CryoStor ${ }^{\circledR} \mathrm{CS} 10$ freezing media, transferred to a CellSeal ${ }^{\circledR}$ Cryovial and placed in a controlled rate freezer before transfer to liquid nitrogen (vapor phase) for long-term storage.

In order to assess the recovery of the cryopreserved product and the effect of cryopreservation on the biology and function of the final product, cells were thawed, diluted in 5\% human serum albumin, and the viability and suppressive function of the cryopreserved product was assessed.

\section{Statistical analysis}

Statistical analysis was carried out on GraphPad Prism 5.0c (GraphPad software Inc. CA, USA). Parametric and nonparametric data were expressed as mean \pm standard error and median where appropriate. For comparison of parametric data, paired and unpaired students t-tests were used. Statistical significance was set at $P<0.05$.

$$
* P<0.05, * * P<0.01 \text { and } * * * P<0.001
$$

\section{ACKNOWLEDGMENTS}

The authors thank all the subjects and patients who volunteered for this study. This research was supported by the MRC Center for Transplantation, British Heart Foundation (BHF), King's College London, UK-MRC Grant no. MR/J006742/1 and the NIHR Biomedical Research Center at Guy's and St Thomas' NHS Foundation Trust and King's College London. The views expressed are those of the author(s) and not necessarily those of the NHS, the NIHR, or the Department of Health.

\section{CONFLICTS OF INTEREST}

The authors declare no financial or commercial conflicts of interest. 


\section{REFERENCES}

1. Lerut $J$ and Sanchez-Fueyo A. An appraisal of tolerance in liver transplantation. American journal of transplantation. 2006; 6:1774-1780.

2. Benitez C, Londono MC, Miquel R, Manzia TM, Abraldes JG, Lozano JJ, Martinez-Llordella M, Lopez M, Angelico R, Bohne F, Sese P, Daoud F, Larcier P, Roelen DL, Claas F, Whitehouse G, et al. Prospective multicenter clinical trial of immunosuppressive drug withdrawal in stable adult liver transplant recipients. Hepatology. 2013; 58:1824-1835.

3. Sakaguchi S, Sakaguchi N, Asano M, Itoh M and Toda M. Immunologic self-tolerance maintained by activated $\mathrm{T}$ cells expressing IL-2 receptor alpha-chains (CD25). Breakdown of a single mechanism of self-tolerance causes various autoimmune diseases. Journal of immunology. 1995; 155:1151-1164

4. Khattri R, Cox T, Yasayko SA and Ramsdell F. An essential role for Scurfin in CD4+CD25+ T regulatory cells. Nature immunology. 2003; 4:337-342.

5. Sakaguchi S, Sakaguchi N, Shimizu J, Yamazaki S, Sakihama T, Itoh M, Kuniyasu Y, Nomura T, Toda M and Takahashi T. Immunologic tolerance maintained by CD25+ CD4+ regulatory $\mathrm{T}$ cells: their common role in controlling autoimmunity, tumor immunity, and transplantation tolerance. Immunological reviews. 2001; 182:18-32.

6. Tsang JY, Tanriver Y, Jiang S, Xue SA, Ratnasothy K, Chen D, Stauss HJ, Bucy RP, Lombardi G and Lechler R. Conferring indirect allospecificity on CD4+CD25+ Tregs by TCR gene transfer favors transplantation tolerance in mice. The Journal of clinical investigation. 2008; 118:36193628 .

7. Sagoo P, Ali N, Garg G, Nestle FO, Lechler RI and Lombardi G. Human regulatory $\mathrm{T}$ cells with alloantigen specificity are more potent inhibitors of alloimmune skin graft damage than polyclonal regulatory $\mathrm{T}$ cells. Science translational medicine. 2011; 3:83ra42.

8. Putnam AL, Safinia N, Medvec A, Laszkowska M, Wray M, Mintz MA, Trotta E, Szot GL, Liu W, Lares A, Lee K, Laing A, Lechler RI, Riley JL, Bluestone JA, Lombardi G, et al. Clinical grade manufacturing of human alloantigenreactive regulatory $\mathrm{T}$ cells for use in transplantation. American journal of transplantation. 2013; 13:3010-3020.

9. Xiao F, Ma L, Zhao M, Huang G, Mirenda V, Dorling A, Lechler R and Lombardi G. Ex vivo expanded human regulatory $\mathrm{T}$ cells delay islet allograft rejection via inhibiting islet-derived monocyte chemoattractant protein-1 production in CD34+ stem cells-reconstituted NOD-scid IL2rgammanull mice. PloS one. 2014; 9:e90387.

10. Li W, Carper K, Zheng XX, Kuhr CS, Reyes JD, Liang Y, Perkins DL, Thomson AW and Perkins JD. The role of Foxp3+ regulatory T cells in liver transplant tolerance. Transplantation proceedings. 2006; 38:3205-3206.

11. Li Y, Koshiba T, Yoshizawa A, Yonekawa Y, Masuda K,
Ito A, Ueda M, Mori T, Kawamoto H, Tanaka Y, Sakaguchi S, Minato N, Wood KJ and Tanaka K. Analyses of peripheral blood mononuclear cells in operational tolerance after pediatric living donor liver transplantation. American journal of transplantation. 2004; 4:2118-2125.

12. Demirkiran A, Kok A, Kwekkeboom J, Kusters JG, Metselaar HJ, Tilanus HW and van der Laan LJ. Low circulating regulatory $\mathrm{T}$-cell levels after acute rejection in liver transplantation. Liver transplantation . 2006; 12:277284.

13. Trzonkowski P, Bieniaszewska M, Juscinska J, Dobyszuk A, Krzystyniak A, Marek N, Mysliwska J and Hellmann A. First-in-man clinical results of the treatment of patients with graft versus host disease with human ex vivo expanded CD4+CD25+CD127- T regulatory cells. Clinical immunology. 2009; 133:22-26.

14. Di Ianni M, Falzetti F, Carotti A, Terenzi A, Castellino F, Bonifacio E, Del Papa B, Zei T, Ostini RI, Cecchini D, Aloisi T, Perruccio K, Ruggeri L, Balucani C, Pierini A, Sportoletti P, et al. Tregs prevent GVHD and promote immune reconstitution in HLA-haploidentical transplantation. Blood. 2011; 117:3921-3928.

15. Brunstein CG, Miller JS, Cao Q, McKenna DH, Hippen KL, Curtsinger J, Defor T, Levine BL, June CH, Rubinstein P, McGlave PB, Blazar BR and Wagner JE. Infusion of ex vivo expanded $\mathrm{T}$ regulatory cells in adults transplanted with umbilical cord blood: safety profile and detection kinetics. Blood. 2011; 117:1061-1070.

16. Marek-Trzonkowska N, Mysliwiec M, Dobyszuk A, Grabowska M, Techmanska I, Juscinska J, Wujtewicz MA, Witkowski P, Mlynarski W, Balcerska A, Mysliwska J and Trzonkowski P. Administration of CD4+CD25highCD127regulatory $\mathrm{T}$ cells preserves beta-cell function in type 1 diabetes in children. Diabetes Care. 2012; 35:1817-1820.

17. Afzali B, Edozie FC, Fazekasova H, Scotta C, Mitchell PJ, Canavan JB, Kordasti SY, Chana PS, Ellis R, Lord GM, John S, Hilton R, Lechler RI and Lombardi G. Comparison of regulatory $\mathrm{T}$ cells in hemodialysis patients and healthy controls: implications for cell therapy in transplantation. Clinical journal of the American Society of Nephrology : CJASN. 2013; 8:1396-1405.

18. Scotta C, Esposito M, Fazekasova H, Fanelli G, Edozie FC, Ali N, Xiao F, Peakman M, Afzali B, Sagoo P, Lechler RI and Lombardi G. Differential effects of rapamycin and retinoic acid on expansion, stability and suppressive qualities of human CD4(+)CD25(+)FOXP3(+) T regulatory cell subpopulations. Haematologica. 2013; 98:1291-1299.

19. Golovina TN, Mikheeva T, Brusko TM, Blazar BR, Bluestone JA and Riley JL. Retinoic acid and rapamycin differentially affect and synergistically promote the ex vivo expansion of natural human T regulatory cells. PloS one. 2011; 6:e15868.

20. Hori S and Sakaguchi S. Foxp3: a critical regulator of the development and function of regulatory T cells. Microbes and infection / Institut Pasteur. 2004; 6:745-751. 
21. Hoffmann P, Boeld TJ, Eder R, Huehn J, Floess S, Wieczorek G, Olek S, Dietmaier W, Andreesen R and Edinger M. Loss of FOXP3 expression in natural human $\mathrm{CD} 4+\mathrm{CD} 25+$ regulatory $\mathrm{T}$ cells upon repetitive in vitro stimulation. European journal of immunology. 2009; 39:1088-1097.

22. Liu W, Putnam AL, Xu-Yu Z, Szot GL, Lee MR, Zhu S, Gottlieb PA, Kapranov P, Gingeras TR, Fazekas de St Groth B, Clayberger C, Soper DM, Ziegler SF and Bluestone JA. CD127 expression inversely correlates with FoxP3 and suppressive function of human CD4+ T reg cells. The Journal of experimental medicine. 2006; 203:1701-1711.

23. Sansom DM and Walker LS. The role of CD28 and cytotoxic T-lymphocyte antigen-4 (CTLA-4) in regulatory T-cell biology. Immunological reviews. 2006; 212:131-148.

24. Read S, Malmstrom V and Powrie F. Cytotoxic T lymphocyte-associated antigen 4 plays an essential role in the function of $\mathrm{CD} 25(+) \mathrm{CD} 4(+)$ regulatory cells that control intestinal inflammation. The Journal of experimental medicine. 2000; 192:295-302.

25. Annunziato F, Cosmi L, Liotta F, Lazzeri E, Manetti R, Vanini V, Romagnani P, Maggi E and Romagnani S. Phenotype, localization, and mechanism of suppression of CD4(+)CD25(+) human thymocytes. The Journal of experimental medicine. 2002; 196:379-387.

26. Ochando JC, Yopp AC, Yang Y, Garin A, Li Y, Boros P, Llodra J, Ding Y, Lira SA, Krieger NR and Bromberg JS. Lymph node occupancy is required for the peripheral development of alloantigen-specific Foxp3+ regulatory T cells. Journal of immunology. 2005; 174:6993-7005.

27. Oo YH, Weston CJ, Lalor PF, Curbishley SM, Withers DR, Reynolds GM, Shetty S, Harki J, Shaw JC, Eksteen B, Hubscher SG, Walker LS and Adams DH. Distinct roles for CCR4 and CXCR3 in the recruitment and positioning of regulatory T cells in the inflamed human liver. Journal of immunology. 2010; 184:2886-2898.

28. Hori S. Developmental plasticity of Foxp3+ regulatory T cells. Current opinion in immunology. 2010; 22:575-582.

29. Li L and Boussiotis VA. The role of IL-17-producing Foxp3 + CD4+ T cells in inflammatory bowel disease and colon cancer. Clinical immunology. 2013; 148:246-253.

30. Pesenacker AM, Bending D, Ursu S, Wu Q, Nistala K and Wedderburn LR. CD161 defines the subset of FoxP3+ T cells capable of producing proinflammatory cytokines. Blood. 2013; 121:2647-2658.

31. Maggi L, Santarlasci V, Capone M, Peired A, Frosali F, Crome SQ, Querci V, Fambrini M, Liotta F, Levings MK, Maggi E, Cosmi L, Romagnani S and Annunziato F. CD161 is a marker of all human IL-17-producing T-cell subsets and is induced by RORC. European journal of immunology. 2010; 40:2174-2181.

32. Cosmi L, De Palma R, Santarlasci V, Maggi L, Capone M, Frosali F, Rodolico G, Querci V, Abbate G, Angeli R, Berrino L, Fambrini M, Caproni M, Tonelli F, Lazzeri E,
Parronchi P, et al. Human interleukin 17-producing cells originate from a CD161+CD4+ T cell precursor. The Journal of experimental medicine. 2008; 205:1903-1916.

33. Afzali B, Mitchell PJ, Edozie FC, Povoleri GA, Dowson SE, Demandt L, Walter G, Canavan JB, Scotta C, Menon B, Chana PS, Khamri W, Kordasti SY, Heck S, Grimbacher $\mathrm{B}$, Tree $\mathrm{T}$, et al. CD161 expression characterizes a subpopulation of human regulatory $\mathrm{T}$ cells that produces IL-17 in a STAT3-dependent manner. European journal of immunology. 2013; 43:2043-2054.

34. Benitez CE, Puig-Pey I, Lopez M, Martinez-Llordella M, Lozano JJ, Bohne F, Londono MC, Garcia-Valdecasas JC, Bruguera M, Navasa M, Rimola A and Sanchez-Fueyo A. ATG-Fresenius treatment and low-dose tacrolimus: results of a randomized controlled trial in liver transplantation. American journal of transplantation. 2010; 10:2296-2304.

35. Marek N, Bieniaszewska M, Krzystyniak A, Juscinska J, Mysliwska J, Witkowski P, Hellmann A and Trzonkowski $\mathrm{P}$. The time is crucial for ex vivo expansion of T regulatory cells for therapy. Cell transplantation. 2011; 20:1747-1758.

36. King MA, Covassin L, Brehm MA, Racki W, Pearson $\mathrm{T}$, Leif J, Laning J, Fodor W, Foreman O, Burzenski L, Chase TH, Gott B, Rossini AA, Bortell R, Shultz LD and Greiner DL. Human peripheral blood leucocyte non-obese diabetic-severe combined immunodeficiency interleukin-2 receptor gamma chain gene mouse model of xenogeneic graft-versus-host-like disease and the role of host major histocompatibility complex. Clinical and experimental immunology. 2009; 157:104-118.

37. Tresoldi E, Dell'albani I, Stabilini A, Jofra T, Valle A, Gagliani N, Bondanza A, Roncarolo MG and Battaglia M. Stability of human rapamycin-expanded CD4+CD25+ T regulatory cells. Haematologica. 2011; 96:1357-1365.

38. Kopf H, de la Rosa GM, Howard OM and Chen X. Rapamycin inhibits differentiation of Th17 cells and promotes generation of FoxP3 $+\mathrm{T}$ regulatory cells. International immunopharmacology. 2007; 7:1819-1824.

39. Qin S, Rottman JB, Myers P, Kassam N, Weinblatt M, Loetscher M, Koch AE, Moser B and Mackay CR. The chemokine receptors CXCR3 and CCR5 mark subsets of $\mathrm{T}$ cells associated with certain inflammatory reactions. The Journal of clinical investigation. 1998; 101:746-754.

40. Lapierre P, Beland K, Yang R and Alvarez F. Adoptive transfer of ex vivo expanded regulatory $\mathrm{T}$ cells in an autoimmune hepatitis murine model restores peripheral tolerance. Hepatology. 2013; 57:217-227.

41. Wells AD, Li XC, Li Y, Walsh MC, Zheng XX, Wu Z, Nunez G, Tang A, Sayegh M, Hancock WW, Strom TB and Turka LA. Requirement for T-cell apoptosis in the induction of peripheral transplantation tolerance. Nature medicine. 1999; 5:1303-1307.

42. Xia G, He J and Leventhal JR. Ex vivo-expanded natural CD4+CD25+ regulatory $\mathrm{T}$ cells synergize with host T-cell depletion to promote long-term survival of allografts. American journal of transplantation. 2008; 8:298-306. 
43. Lopez M, Clarkson MR, Albin M, Sayegh MH and Najafian N. A novel mechanism of action for anti-thymocyte globulin: induction of CD4+CD25+Foxp3+ regulatory $\mathrm{T}$ cells. Journal of the American Society of Nephrology. 2006; 17:2844-2853.

44. Strauss L, Whiteside TL, Knights A, Bergmann C, Knuth A and Zippelius A. Selective survival of naturally occurring human $\mathrm{CD} 4+\mathrm{CD} 25+$ Foxp3+ regulatory $\mathrm{T}$ cells cultured with rapamycin. Journal of immunology. 2007; 178:320329. 